\title{
DEVELOPMENT OF THE APPROACHES FOR COMPLEX UTILIZATION OF BROWN ALGAE (FUCUS VESICULOSUS) BIOMASS FOR THE OBTAINING OF VALUE-ADDED PRODUCTS
}

Oskars BIKOVENS, Latvian State Institute of Wood Chemistry, Laboratory of Lignin Chemistry, Dzerbenes 27, Riga, LV1006, Latvia; bikovens@edi.lv (corresponding author)

Jevgenija PONOMARENKO, Latvian State Institute of Wood Chemistry, Laboratory of Lignin Chemistry, Dzerbenes 27, Riga, LV1006, Latvia; jevgenijaponomarenko@inbox.lv

Sarmite JANCEVA, Latvian State Institute of Wood Chemistry, Laboratory of Lignin Chemistry, Dzerbenes 27, Riga, LV1006, Latvia; sarmite.janceva@inbox.lv

Maris LAUBERTS, Latvian State Institute of Wood Chemistry, Laboratory of Lignin Chemistry, Dzerbenes 27, Riga, LV1006, Latvia; lauberts@edi.lv

Laima VEVERE, Latvian State Institute of Wood Chemistry, Laboratory of Lignin Chemistry, Dzerbenes 27, Riga, LV1006, Latvia; vevere@inbox.lv

Galina TELYSHEVA, Latvian State Institute of Wood Chemistry, Laboratory of Lignin Chemistry, Dzerbenes 27, Riga, LV1006, Latvia; ligno@edi.lv

\begin{abstract}
The seaweed collected after stranding on beaches of Latvia is underexploited natural resource, which has a potential as raw material for biologically active compound extraction for cosmetic and pharmacy and fertilizer in sustainable agriculture. The aim of the present study was development of the approach for the processing of brown alga Fucus vesiculosus biomass, collected from the Gulf of Riga. The thorough characterization of the chemical composition of Fucus vesiculosus has shown that it is a potential source for obtaining of nitrogen-containing fertilizers, and biologically active compounds. One of the proposed approaches for the processing of the Fucus vesiculosus biomass under study includes algae extraction with organic solvents and $\mathrm{CaCl}_{2}$ solution and obtaining soil organic amendment on the basis of the extract-free residue. The ethyl acetate extract was rich in phenolic compounds (430 $\pm 30 \mathrm{GAE} \mathrm{mg} / \mathrm{g})$ with high antioxidant activity in $\mathrm{DPPH}^{*}$ and $\mathrm{ABTS}^{-+}$tests. The ethanol extract contained significant amounts of phlorotannins that was confirmed by the data of LC-MS/MS analysis. The $\mathrm{CaCl}_{2}$ extract was used for the obtaining of sulphated polysaccharide fucoidane (yield $\approx 7 \%$ on the basis of oven dry matter, o.d.m.), which has numerous biological activities. The extract-free residue didn't show phytotoxicity. The extract free algal biomass exhibited positive effect in root elongation tests with oat (Avena sativa). As alternative approach for processing of the algal biomass, the mechano-chemical treatment of algal biomass with lignin was proposed. EPR analyses confirmed interaction between algal biomass and lignin.
\end{abstract}

Keywords: Fucus vesiculosus, extracts, antioxidants, organic fertilizers, biorefinery

\section{INTRODUCTION}

Latvian bioeconomical development requires effectively utilize available natural resources and seaweeds are one of the underexploited local resources (Bioeconomy strategy..., 2017). The shores of the Baltic Sea in Latvia are almost $500 \mathrm{~km}$ long, and thousands tons of seaweeds every year are washed ashore. According to EU Directive 2006/7/EC, washed out algae have to be collected by local municipalities during the beach season in recreation places.

Washed out algae have been used for centuries as a natural fertilizer. However, rapid application of algal biomass is possible not always, but storage of the algal biomass results in emission of odors and release of a liquefied fraction (Michalak et al. 2013). Seaweed processing is focused mainly on hydrocolloids production which is large scale and growing industry (Porse et al. 2017), however seaweeds treatment plant in Latvia ("Nakotne", Dobele) was closed in early nineties (Grickus et al. 2013). One of the reasons for it was extreme decrease of red algae Furcellaria lumbricalis habitat in Latvia coastal zone after the oil spill from tanker in 1979 near Ventspils and in 1981 near Klaipeda (Korolev et al. 2004). To our knowledge at the present moment "Est-Agar" AS (Estonia) is the only plant in Baltic States which produces the hydrocolloid furcellaran from Furcellaria lumbricalis.

The dominant macroalgae in the Baltic Sea and the Gulf of Riga is Fucus vesiculosus (Seisuma et al. 2011). In many countries brown algae have wide application in several area such as human and animal nutrition, cosmetic and fertilizers (Rioux et al. 2015). However, brown algae $F$. vesiculosus can accumulate heavy metals from marine water

Copyright (C) 2017 The Authors. Published by Aleksandras Stulginskis University. This is an open-access article distributed under the terms of the Creative Commons Attribution License (CC-BY 4.0), which permits unrestricted use, distribution, and reproduction in any medium, provided the original author and source are credited. 
(Seisuma et al. 2011) which limits their application for nutrition or medicine. F. vesiculosus contain various biologically active compounds with potential market value such as sulfated polysaccharide fuciodan (Ale et al. 2011), phlorotannins (Kirke et al. 2017) etc. The interest in algae based chemicals have increased over the past few years. An effective biorefinery approach for algae processing can only be achieved by integration with other industries. It is necessary to establish a proper connection between the various input and output flows of the products, as well as the services provided by the participating industries. Nowadays many researches are focused on production of biodiesel and biogas from algae (Dong et al. 2016, Balina et al. 2015). The development of integrated algae biorefinery process capable of producing multiple products is crucial for the commercialization of the Latvian underused valuable resource.

The aim of present study was complex utilization of Fucus vesiculosus biomass for the obtaining of high value-added niche products such as natural antioxidants, well known bioactive polisaccharide fucoidan, and fertilizers on the basis of solid residual biomass of $F$. vesiculosus after extraction.

\section{MATERIALS AND METHODS}

Seaweeds were manually collected on the beach area of Gulf of Riga in Jurmala (Latvia) in March 2017. The algae were identified using a taxonomical identification key (Rudzorga 1995). The samples of algae were washed with deionized water, separated and freeze-dried. Before chemical analyses algae were refined in knife-type mill and then additionally finely ground in a Retsch Mixer Ball Mill MM200.

Elemental composition and ash content. The $\mathrm{C}, \mathrm{H}, \mathrm{N}$, and $\mathrm{S}$ contents were measured according to LVS EN 15104:2011 using a Vario MACRO elemental analyzer. Ash content was measured as a residue after treatment at $550{ }^{\circ} \mathrm{C}$ in a Carbolite ELF 11/6B furnace.

Content of extractable compounds. Sequential extraction with hexane, ethyl acetate (both in Soxhlet apparatus, $8 \mathrm{~h}$ ), boiling $80 \%$ aqueous ethanol (batch extraction, $1 \mathrm{~h} \times 3$ times) followed by hot $2 \% \mathrm{CaCl}_{2}$ solution $\left(70{ }^{\circ} \mathrm{C}, 1 \mathrm{~h} \times 3\right.$ times) was performed. The yield of extractable in organic solvent compounds was determined gravimetrically after evaporating the solvent under vacuum. The yield of extractable in $\mathrm{CaCl}_{2}$ solution compounds was determined by weight difference before and after extraction. $\mathrm{CaCl}_{2}$ solution after extraction were dialyzed against deionized water (Spectra/Por Dialysis Membrane 6, molecular weight cut-off $=1000 \mathrm{Da}$ ) and then freeze-dried.

Chemical analysis. The content of phenolic compounds in the extracts was determined by the Folin-Ciocalteu method with gallic acid as reference. Results are expressed in gallic acid equivalent (GAL mg/g of dry extract). Radical scavenging activity was performed against stable radicals DPPH ${ }^{\bullet}$ and ABTS ${ }^{+}$using spectrophotometric method (Miliauskas et al. 2004). Free radical scavenging activity is expressed by $\mathrm{IC}_{50}$, which means the concentration required for $50 \%$ inhibition of free radicals. Neutral sugar composition was determined using alditol acetate method after treatment with sulfuric acid (Blakeneyet al. 1983). Alditol acetates were quantified by gas chromatography (Agilent 6850 Series GC System, column TC17) using methyl $\alpha$-D-glucopyranoside as an internal standard. The FTIR spectra were recorded with Perkin Elmer Spectrum One spectrometer. LC MS/MS analysis was performed using ACQUITY UPLC H-Class (Waters) with ACQUITY UPLC PDA Detector coupled with SYNAPT G2-Si High Definition Mass Spectrometry (Waters), column - UPLC BEH C18. Mobile phase A: water $+0.1 \%$ formic acid, B: acetonitrile, gradient from $5 \%$ to $100 \%$ B. Mass range (50-1200 Da). EPR spectra were recorded with a Bruker EMX spectrometer operating at 9.6-GHz and a $50-\mathrm{kHz}$ magnetic field modulation.

The germination test. The algae and algae containing mixtures (33\% algae or solid algae residue after extraction and $67 \%$ lignin on o.d.m.) were tested by their effect on cress seeds germination. The seeds were sprouted on a filter paper by wetting it with $50 \mathrm{mg}$ of the tested composition per $10 \mathrm{~g}$ of distilled or deionized water. The germination experiments were carried out in three replicates, each with 20 seeds. Cress seeds were sprouted at $20-25^{\circ} \mathrm{C}$ for five days in the dark. The analysis of the sprouted seeds (the length of the shoot and the root) was performed using the WinRHIZO (EPSON PERFECTION 4990 PHOTO scanner).

The biological activity of the algae preparations. The effect of the algae samples under study on growth of the oat seeds was tested. The vegetation tests were carried out in the $50 \mathrm{~mL}$ containers, which were filled with the soil substrate „Sulfinor" and placed in the precision climate chamber (Selecta HOTCOLD-GL 2101507). The soil contained $>90 \%$ of organic matter, $\mathrm{pH} 5.5-6.5 ; \mathrm{Ca}-1.1 \%, \mathrm{Mg} 0.06 \%$, humidity $60 \%$, fraction size $0-10 \mathrm{~mm}$. The dose of algae containing samples was $5-10 \pm 0.1 \mathrm{~g} / \mathrm{kg}$. The oat seeds were placed in the containers filled with the soil at a depth of $1 \mathrm{~cm} .20 \mathrm{seeds}$ were used per one experiment. The condition of the germination and growth of the oat seeds were as follows: $18{ }^{\circ} \mathrm{C}$, humidity $90 \%$, luminous intensity $30 \%$, experiment length 15 days. After 15 days a root system analysis (length, average diameter, root volume, count of tips, count of forks) was performed using the WinRHIZO.

\section{RESULTS AND DISCUSSIONS}

Collected seaweeds were identified mainly as Fucus vesiculosus - a brown macroalga common on the shores of Baltic Sea. The amount of other algae such as Furcellaria lumbricalis was low; therefore they were not analyzed in details in the present study. Elemental composition and ash content of collected $F$. vesiculosus is listed in Table 1 and in general it coincides with literature results (Balina et al. 2016).

The results of sequential extraction of $F$. vesiculosus with solvents of increasing polarity have shown that $F$. vesiculosus is low in hexane soluble lipophilic compounds (Table 2). FTIR spectra of bad smelling green hexane extract showed that it contains unsaturated fatty acids (strong absorption at 3010, 2925, 2854, 1740, 1660, 1460, $720 \mathrm{~cm}^{-1} \mathrm{of}$ 
various $-\mathrm{CH},-\mathrm{CH}_{2},-\mathrm{C}=\mathrm{C}$ and ester group vibrations), but the yield of hexane extract was low ( 1\% o.d.m. of algae). UV and FTIR spectra showed that ethyl acetate and ethanol extract are rich in phenolic compounds which are responsible for free radical scavenging activity. Ethanol extract have a positive reaction with vanillin-HCl typical for meta- substituted phenols e.g. in tannins. LC-MS/MS analysis confirmed that ethanol and also ethyl acetate extract contained phlorotannins. Vanillin assay allows estimating tannin content in ethanol extract as approx. $10 \%$.

Table 1. Ash content and elemental composition of Fucus vesiculosus (\% of dry weight)

\begin{tabular}{|l|c|c|c|c|c|c|}
\hline & Ash, \% & $\mathrm{C}$ & $\mathrm{H}$ & $\mathrm{N}$ & $\mathrm{S}$ & C/N ratio \\
\hline F. vesiculosus & $18.5 \pm 0.1$ & $39.6 \pm 0.1$ & $4.27 \pm 0.08$ & $2.22 \pm 0.01$ & $2.30 \pm 0.1$ & 17.8 \\
\hline $\begin{array}{l}\text { F. vesiculosus } \\
\text { residue after } \\
\text { extraction }\end{array}$ & $19.7 \pm 0.1$ & $38.5 \pm 0.2$ & $4.05 \pm 0.02$ & $2.24 \pm 0.03$ & $0.63 \pm 0.5$ & 17.2 \\
\hline
\end{tabular}

Table 2. Yield of extracts from Fucus vesiculosus, total phenols content in extracts and their antioxidant activity (IC50, mg/L).

\begin{tabular}{|l|c|c|c|c|}
\hline Extractant & Yield, \% o.d.m. & Phenols, GAE mg/g & DPPH* test & ABTS ${ }^{+}$test \\
\hline Hexane & $0.9 \pm 0.2$ & n.d. & n.d. & n.d. \\
\hline Ethylacetate & $3.1 \pm 0.1$ & $430 \pm 30$ & 28.5 & 1.8 \\
\hline $80 \%$ ethanol & $7.3 \pm 0.4$ & $230 \pm 10$ & 57.7 & 4.4 \\
\hline $2 \% \mathrm{CaCl}_{2}$ & $10.1 \pm 0.2$ & n.d. & $>500 *$ & $52^{*}$ \\
\hline
\end{tabular}

n.d. - not determined, * - after extract dialysis

Amount of neutral sugars after hydrolysis was higher in more polar ethanol extract (Table 3). Probably sugars present in both extracts as part of glucosides - in ethyl acetate extract mainly as galactosides, but in ethanol extract as mannosides. Ethyl acetate extract contains almost double amount of phenolic compounds than ethanol extract. Radical scavenging activity of ethyl acetate extract against DPPH $\cdot$ and ABTS $\cdot{ }^{+}$radicals is significantly higher than that for ethanol extract. The ABTS ${ }^{++} \mathrm{IC}_{50}$ value of ethyl acetate extract of $F$. vesiculosus is lower than those for commercial synthetic antioxidant s Trolox, TBHQ, and natural antioxidants, e.g., analogues alder bark extract (Telyshevaet al. 2011). Thisdemosntrates that $F$. vesiculosus extracts could be potential natural alternative to synthetic antioxidants.

Extraction with $\mathrm{CaCl}_{2}$ was used to isolate biologically active polysaccharide fucoidan. Obtained fucoidan after dialysis and freeze-drying was pale yellow powder with the yield $\sim 7$ from alga. FTIR spectra confirmed presence of sulfate group (absorption at 1230, $845 \mathrm{~cm}^{-1} \mathrm{~S}=\mathrm{O}$ asymmetric vibration and ester bond) (Wang et al. 2010). Elemental analysis showed that fucoidan contained $7.0 \pm 0.2 \%$ sulphur or $\sim 20 \%$ sulfate groups. Although isolated fucoidan did not exhibit significant antioxidant activity in tests with stable radicals, it is characterized with various biological activities (Ale et al. 2011), which made it prospective niche product from $F$. vesiculosus.

Algal biomass contains significant amount of various polysaccharides (Rioux et al. 2015). Unlike terrestrial plants, brown algae contain lower amount of neutral sugars. Main monosaccharide of $F$. vesiculosus is fucose. After extraction, total neutral sugar amount increased from $\sim 24 \%$ to $29 \%$ (Table 3 ).

Nitrogen containing compounds content after extraction did not change (Table 1), however relative amount of protein in biomass increased 2.5 times according to the amino acid assay by ninhydrin colorimentric method. Probably part of non-protein nitrogen containing compounds, e.g., chlorophyll, was removed during extraction.

Table 3. Neutral sugar composition of Fucus vesiculosus before and after extraction and in extracts (\% of dry weight).

\begin{tabular}{|l|c|c|c|c|c|c|c|}
\hline & Fuc* & Ara & Xyl & Man & Gal & Glc & Total \\
\hline F. vesiculosus & $10.9 \pm 1.0$ & $0.5 \pm 0.1$ & $2.0 \pm 0.1$ & $2.8 \pm 0.4$ & $1.8 \pm 0.1$ & $6.6 \pm 0.3$ & 24.6 \\
\hline $\begin{array}{l}\text { F. vesiculosus } \\
\text { ethyl acetate } \\
\text { extract }\end{array}$ & $0.47 \pm 0.09$ & $0.36 \pm 0.19$ & - & $0.46 \pm 0.05$ & $2.74 \pm 0.16$ & - & 4.1 \\
\hline $\begin{array}{l}F . \text { vesiculosus } \\
\text { ethanol extract }\end{array}$ & $0.18 \pm 0.07$ & $0.44 \pm 0.14$ & - & $8.7 \pm 0.5$ & $1.11 \pm 0.05$ & $0.84 \pm 0.04$ & 11.3 \\
\hline $\begin{array}{l}F . \text { vesiculosus } \\
\text { after extraction }\end{array}$ & $12.1 \pm 1.2$ & $0.5 \pm 0.1$ & $2.7 \pm 0.2$ & $3.0 \pm 0.4$ & $1.9 \pm 0.2$ & $8.7 \pm 0.4$ & 28.9 \\
\hline
\end{tabular}

* Fuc - fucans, Ara - arabinans, Xyl - xylans, Man - mannans, Gal - galactan, Glc - glucans.

Relatively low $\mathrm{C} / \mathrm{N}$ ratio detected for $F$. vesiculosus biomass did not change significantly during extraction and was comparable with commercial grass compost (Bikovens et al, 2010). The addition of algae to tested mixture showed beneficial effect on cress (Lepidium sativum) seeds germination and root system development. The addition of the algal biomass to soil promoted the growth and development of the root system of the oat (Avena sativa) seeds. The effect of $F$. vesiculosus was dose-depended and was noticeable after $5 \mathrm{~g} / \mathrm{kg}$ addition. Oat root length, amount of roots tips and forks increase were more prominent when $F$. vesiculosus residue after extraction was used (Table 4). The comparison of the unextracted algae and algae residue, obtained after extraction of fucoidan, showed, that the latter has stronger positive effect on the oat seeds growth and germination.

As alternative approach for processing of the $F$. vesiculosus biomass, the mechanochemical treatment of algae biomass with hydrolyses lignin was proposed. EPR analyses confirmed interaction between algae biomass and lignin. Free spin concentration in algal-lignin complex is more than 2 times lower $\left(4.3 * 10^{15} \mathrm{spin} / \mathrm{g}\right)$ in comparison with $F$. vesiculosus biomass $\left(1.2 * 10^{16} \mathrm{spin} / \mathrm{g}\right)$ and lignin $\left(1.1^{*} 10^{16} \mathrm{spin} / \mathrm{g}\right)$. Currently the vegetation tests are carried out for estimation of novel fertilizer effects on plants growth and development. 
Table 4. Effect of addition of Fucus vesiculosus in the soil on oat growth.

\begin{tabular}{|l|c|c|c|c|c|}
\hline & Root length, $\mathrm{cm}$ & $\begin{array}{c}\text { Average diameter, } \\
\mathrm{mm}\end{array}$ & Root volume, $\mathrm{cm}^{3}$ & Count of tips & Count of forks \\
\hline Control & $55 \pm 9$ & $0.40 \pm 0.05$ & $0.10 \pm 0.02$ & $394 \pm 54$ & $294 \pm 71$ \\
\hline $\begin{array}{l}F . \text { vesiculosus in } \\
\text { the soil } 5 \mathrm{~g} / \mathrm{kg}\end{array}$ & $61 \pm 12$ & $0.40 \pm 0.05$ & $0.10 \pm 0.02$ & $372 \pm 48$ & $345 \pm 64$ \\
\hline $\begin{array}{l}F . \text { vesiculosus in } \\
\text { the soil }(10 \mathrm{~g} / \mathrm{kg})\end{array}$ & $88 \pm 14$ & $0.40 \pm 0.05$ & $0.10 \pm 0.02$ & $688 \pm 61$ & $338 \pm 52$ \\
\hline $\begin{array}{l}F . \text { vesiculosus } \\
\text { after extraction in } \\
\text { the soil }(5 \mathrm{~g} / \mathrm{kg})\end{array}$ & $70 \pm 7$ & $0.40 \pm 0.04$ & $0.10 \pm 0.02$ & $664 \pm 56$ & $353 \pm 42$ \\
\hline
\end{tabular}

\section{CONCLUSIONS}

The present work proposes complex processing of the brown algae Fucus vesiculosus biomass, which can be collected at the costs of the Baltic Sea. The promising approach includes the extraction of the fucoidan, phenolic compounds with biological and antioxidant activities important for pharmaceutical, cosmetic and food industries and the use of the residue after extraction as a fertilizer in agriculture. The studied algae biomass is not phytotoxic, promotes the growth of the agricultural plants and has a good potential in sustainable agriculture. The mechanochemical treatment was proposed for obtaining novel fertilizer based on algal biomass.

\section{ACKNOWLEDGEMENT}

This research was funded by a Bio-economic grant "LigProBK" from the Latvian State Institute of Wood Chemistry.

\section{REFERENCES}

1. Ale, M.T., Mikkelsen, J.D., Meyer A.S. 2011. Important determinants for fucoidan bioactivity: a critical review of structurefunction relation and extraction methods for fucose-containing polysaccharides from brown seaweeds. Marine Drugs, Vol. 9, pp. 2106-2130. https://doi.org/10.3390/md9102106

2. Balina, K., Romagnoli, F., Blumberga, D. 2016. Chemical composition and potential use of Fucus vesiculosus from Gulf of Riga. Energy Procedia, Vol. 95, pp. 43-49. https://doi.org/10.1016/j.egypro.2016.09.010

3. Bikovens, O., Telysheva, G., Iiyama, K. 2010. Comparative studies of grass compost lignin and the lignin component of compost humic substances. Chemistry and Ecology, Vol. 26 (S2), pp. 67-75. https://doi.org/10.1080/02757540.2010.494600

4. Bioeconomy strategy of Latvia $2030 \quad$ (Iin $\quad$ Latvian). Available at http://tap.mk.gov.lv/lv/mk/tap/?pid=40433525\&mode=mk\&date=2017-12-19 (accessed on 25/01/2018)

5. Blakenet, A.B., Harris, P.J., Henry, R.J., Stone, B.A. 1983. A simple and rapid preparation of alditol acetate for monosaccharide analysis. Carbohydrate Research, Vol. 113, pp. 291-299. https://doi.org/10.1016/0008-6215(83)88244-5

6. Dong, T., Knoshaug, E.P., Davis, R., Laurens, L.M.L., Van Wychen, S., Pienkos P.T. Nagle, N. 2016. Combined algal processing: A novel integrated biorefinery process to produce algal biofuels and bioproducts. Algal Research, Vol. 19, pp. 316-323. https://doi.org/10.1016/j.algal.2015.12.021

7. Grickus, A., Jelagina, K. 2013. Development plan for the potential resumption of agar production from red algae Furcellaria in the Latvian coastal region Kurzeme. SUBMARINER Report 3/2012: http://www.submariner-project.eu/

8. Kirke, D.A., Smyth, T.J., Rai, D.K., Kenny, O., Stengel, D.B. 2017. The chemical and antioxidant stability of isolated low molecular weight phlorotannins. Food Chemistry, Vol. 221, pp. 1104-1112. https://doi.org/10.1016/j.foodchem.2016.11.050

9. Korolev, A., Fetter, M. 2004. Monitoring of macro algae and blue mussels stocks in the eastern Baltic. USA-Baltic International symposium. Article no. 7296834. https://doi.org/10.1109/BALTIC.2004.7296834

10. Michalak, I., Chojnacka, K. 2013. Algal compost - toward sustainable fertilization. Reviews in Inorganic Chemistry, Vol. 33, pp. 161-172. https://doi.org/10.1515/revic-2013-0006

11. Miliauskas, G., Venskutonis, P.R., Van Beek, T.A. 2004. Screening of radical scavenging activity of some medicinal and aromatic plant extracts. Food Chemistry, Vol. 85, pp. 231-237. https://doi.org/10.1016/j.foodchem.2003.05.007

12. Porse, H., Rudolph, B. 2017. The seaweed hydrocolloids industry: 2016 updates, requirements, and outlook. Journal of Applied Phycology, Vol. 29, pp. 2187-2200. https://doi.org/10.1007/s10811-017-1144-0

13. Rioux, L.E., Turgeon, S.L. 2015. Seaweed Carbohydrates. In book: Seaweed Sustainability. Elsevier Inc.

14. Rudzorga, A. 1995. Izplatītāko alı́gu noteicējs. Zinātne, Riga. [In Latvian]

15. Seisuma, Z., Kuḷikova, I., Botva, U., Boikova, E. 2011. Long-term investigation of metal concentrations in brown algae Fucus vesiculosus from the Gulf of Riga, Baltic Sea. Proc Latvian Academy of Sciences, Section B, Vol. 65(5/6), pp. 186-191. https://doi.org/10.2478/v10046-011-0035-Z

16. Telysheva, G., Dizhbite, T., Bikovens, O., Ponomarenko, J., Janceva, S., Krasilnikova, J. 2011. Structure and antioxidant activity of diarylheptanoids extracted from bark of grey alder (Alnus incana) and potential of biorefinery-based bark processing of European trees. Holzforschung, Vol. 65, Iss. 4, p. 623-629. https://doi.org/10.1515/hf.2011.096

17. Wang, J., Zhang, Q., Zhang, Z., Song, H., Li, P. 2010. Potential antioxidant and anticoagulant capacity of low molecular weight fucoidan fractions extracted from Laminaria japonica. International Journal of Biological Macromolecules, Vol. 46, pp. 6-12. https://doi.org/10.1016/j.ijbiomac.2009.10.015 